\title{
Acesso ao SUS: representaçôes e práticas de profissionais desenvolvidas nas Centrais de Regulação
}

I 1 Ana Raquel Bonder Gawryszewski, 2 Denize Cristina Oliveira, ${ }^{3}$ Antonio Marcos Tosoli Gomes I

Resumo: A universalização das ações e serviços, promovida pelo SUS, tem sido caracterizada como excludente e acompanhada de racionalização do financiamento e da inclusão de toda a população na atenção pública à saúde. Este estudo analisa a política de hierarquização do SUS como mecanismo do planejamento, por meio das práticas institucional e profissional desenvolvidas nas Centrais de Regulação. O objetivo é apreender e analisar as representações sociais do acesso às ações e serviços de saúde pelos técnicos e gerentes dessas Centrais no município do Rio de Janeiro. O campo de estudo compreendeu as Centrais de Regulação de Urgência e Estadual de Regulação de Leitos. Foram entrevistados 20 sujeitos e realizada análise de conteúdo. Como resultados destacam-se as seguintes categorias representacionais: a atitude assumida diante da organização e fluxo para o acesso; Papéis e práticas da regulação; fragmentação da autonomia da regulação; rede de relacionamentos determinando o acesso; e ausência de comando único. A fragilidade do sistema público de saúde apresenta-se exposta, e as práticas nas centrais de regulação são pouco efetivas e dependentes de mecanismos não formais de ação. Observa-se um SUS menos consolidado no Rio de Janeiro quando comparado a municípios que avançam enfrentando de forma unificada, regionalizada e hierarquizada o acesso às açôes do SUS. Destaca-se que as centrais de regulação são espaços privilegiados para observação do sistema, podendo realizar açôes efetivas e ágeis, facilitando o acesso aos serviços e propiciando um canal sensível para o atendimento das demandas de saúde da população.
1 Médica, mestre pela Faculdade de Enfermagem da UERJ. Endereço eletrônico: anabonder@gmail.com

${ }^{2}$ Enfermeira. Doutora em Saúde Pública pela Escola de Saúde Pública da USP e Pós-doutora em Psicologia Social pela École de Hautes Etudes en Sciences de L'Homme/Paris. Professora titular da Faculdade de Enfermagem da UERJ.

${ }^{3}$ Enfermeiro. Doutor em Enfermagem pela Escola de Enfermagem Anna Nery da UFRJ. Pós-Doutor em Enfermagem pela Universidade Federal de Santa Catarina. Professor Titular da Faculdade de Enfermagem da UERJ.
Recebido em: 10/12/2009. Aprovado em: 19/08/2010. 


\section{Introdução}

O Sistema Único de Saúde (SUS) é uma política pública que vem sendo construída em um contexto de dimensões políticas, tecnológicas, ideárias e sociais. Ao mesmo tempo, percebe-se que um dos maiores desafios a ser vencido pelo próprio sistema é a ampliação do acesso a suas ações e serviços. Nesse sentido, considerase que o processo de universalização das ações e dos serviços promovido pelo SUS tem sido caracterizado como excludente, embora tenha sido acompanhado de um processo de racionalização do financiamento e da inclusão de todas as camadas sociais na atenção pública à saúde.

Ao estabelecer uma relação dessa definição com os serviços de saúde, o acesso pode ser entendido como "porta de entrada", como o local de acolhimento do usuário no momento da expressão de sua necessidade e, de certa forma, como os caminhos por ele percorridos no sistema na busca da resolução dessa necessidade (ABREU; JESUS, 2006).

Vivemos, hoje, um cenário de consolidação do SUS (SES DF, 2004), no qual a organização da atenção e da assistência à saúde e a ampliação do acesso dos cidadãos aos serviços constituem os principais desafios para os gestores nas três esferas de governo: municipal, estadual e federal. Esses desafios expressam a inclusão assistencial de um grande contingente populacional, antes desassistido ou assistido restritamente, a fusão das redes assistenciais e as ações de gestão necessárias para que essa inclusão e concretize.

No período compreendido entre 1998 e 2001, o Ministério da Saúde empreendeu grandes esforços para a consolidação do SUS, organizando as redes assistenciais, ampliando o acesso da população aos diferentes serviços de saúde e ampliando a qualidade e a resolutividade da assistência prestada. Para tanto, o ministério adotou duas linhas de ação estratégicas e fundamentais: a ampliação da atenção básica e a regionalização e organização da assistência à saúde (BRASIL, 2004).

Os dispositivos legais que pontuam o acesso e a regulação das ações têm como marco a publicação da NOAS 2001/2002, que define a regulação assistencial; bem como a publicação da Portaria SAS/MS no 729/2002, que estabelece os indicadores destinados tanto a orientar a elaboração, quanto a avaliar a implementação dos Planos de Regulação, Controle e Avaliação de estados e municípios. A Portaria GM/MS no 399/2006, por sua vez, estabelece 
as Diretrizes Operacionais do Pacto pela Vida em Defesa do SUS e de Gestão; e a Portaria GM/MS no 699/2006 regulamenta a implantação dos Pactos pela Vida e Gestão do SUS e institui o Termo de Compromisso de Gestão.

O planejamento do sistema de saúde utiliza um arsenal de mecanismos jurídicos e normativos que visam a garantir e ampliar o acesso aos serviços e aos procedimentos necessários ao atendimento dentro do SUS. Esses mecanismos compreendem atenção básica resolutiva, encaminhamentos responsáveis e adequados, e protocolos assistenciais e complexos reguladores, entre outros aspectos. Uma política de regulação pautada pelo cuidado integral deve programar ações-meio que facilitem a boa terminalidade das ações de atenção, tais como: assegurar o acesso aos exames dos usuários da atenção básica; agilizar o processo de autorizações; e garantir o acesso dos usuários às consultas médicas, terapias ou exames.

Dentre essas ações, encontram-se as de regulação da atenção à saúde, que são responsáveis por disponibilizar, nos casos de internação, os leitos referenciados na medida da gravidade/emergência do problema, da complexidade tecnológica e da resposta exigida (BRASIL, 2004). A regulação do acesso à assistência tem como objetos a organização, o controle, o gerenciamento e a priorização do acesso e dos fluxos assistenciais no âmbito do SUS, efetivada pela disponibilização da alternativa mais adequada à necessidade do cidadão, por meio de atendimentos às urgências, consultas, exames, leitos e outros que se fizerem necessários (BRASIL, 2007).

À medida que a regulação assistencial busca organizar a oferta de serviços, exige também que sua interface vá além dos sujeitos envolvidos na ação, perpassando a pactuação com os serviços públicos e, também, com os privados - estes últimos identificados como necessários para a complementaridade assistencial. Nesse contexto, deve-se pontuar que a regulação assistencial é atravessada por quatro linhas de força - o Estado, os serviços privados, os trabalhadores na sua ação cotidiana e os usuários que buscam os serviços -, caracterizando um sistema contraditório e repleto de tensões, próprio de um cenário complexo e que contempla diferentes sujeitos no curso da sua ação. Essa rede de forças e de relações acaba por determinar o melhor ou o pior resultado da ação das Centrais de Regulação, ora privilegiando os interesses individuais, ora os coletivos, por um lado, e ora os públicos, ora os privados, por outro, em função da rede de tensôes que se estabelece. 
Este estudo analisa a política de hierarquização do sistema de saúde como mecanismo do planejamento por meio das representaçóes e das práticas institucional e profissional desenvolvidas nas Centrais de Regulação. Seus objetivos são apreender e analisar as representações sociais do acesso às açôes e aos serviços de saúde entre técnicos e gerentes das Centrais de Regulação do município do Rio de Janeiro, buscando descrever as barreiras e facilidades ao acesso, bem como identificar as representações sociais e discutir as relações estabelecidas entre estas e as práticas profissionais desenvolvidas.

Neste trabalho, portanto, discute-se um dos grandes desafios a ser vencido pelo SUS - a ampliação do acesso, como já pontuado -, por intermédio da apreensão da lógica comum, do código partilhado nas representações sociais construídas por profissionais atuando em centrais de regulação, e na sua inter-relação com as práticas profissionais e institucionais. Destaca-se que o presente estudo está vinculado ao projeto integrado de pesquisa intitulado "As políticas municipais de saúde no contexto do SUS: memórias e representaçôes das instituiçōes, dos profissionais e dos usuários na cidade do Rio de Janeiro", coordenado pela professora Denize Cristina de Oliveira e desenvolvido no grupo de pesquisa "A promoção da saúde e as práticas de cuidado de enfermagem e saúde de grupos populacionais".

\section{Trajetória metodológica}

O referencial teórico-metodológico está fundamentado em quatro aspectos: o contexto histórico das políticas de saúde; o processo de construção do SUS; os dispositivos legais que buscam garantir o acesso e sua regulação; e a Teoria das Representações Sociais.

O contexto histórico traz em princípio a organização da assistência na década de 30, baseada nos institutos de previdências de trabalhadores do comércio, bancários, industriários e servidores públicos, no bojo da reforma sanitária como estruturante para o SUS. A legislação iniciada com a NOAS 2001 formula o arcabouço jurídico que dá norte à nova organização dos serviços de saúde.

Bitencourt e Hortale (2007) apontam a decadência do sistema hospitalocêntrico e sua substituição por um modelo com maior integração dos serviços, pelo desenvolvimento de redes assistenciais, para fazer frente à atenção integral à saúde da população, com acesso irrestrito, devidamente regulado e 
interligado por corredores virtuais. Os autores ainda explicitam, em sua avaliação

das superlotações dos hospitais, que as intervenções dentro da dinâmica gerencial interferem ativa e positivamente no fluxo dos pacientes. Destacam-se: unidade de pronto-atendimento; bed czar ou gerente de leitos; coordenação de altas do SEH; prontuários eletrônicos; equipes de alto desempenho clínico; laboratório-satélite; indicadores de saturação operacional; censo de vagas e demandas; encaminhamento rápido para sala de observação clínica; busca ativa dos pacientes internados no SEH; coordenação de alta hospitalar; pré-alta; sala de alta; cancelamento de internações eletivas; redistribuição de cirurgias eletivas (BITENCOURT; HORTALE, 2007, p. 935);

O outro eixo, a Teoria das Representações Sociais (RS), engloba em seu contexto os comportamentos individuais e coletivos e o meio social, destituindoos de neutralidade. Na sua função prática, destaca-se a importância da RS é que ela serve para agir sobre o mundo e sobre os outros. Se uma representação social é uma "representação para a ação", ela não o é somente na medida em que guia o comportamento, mas, sobretudo, na medida em que remodela e reconstitui os elementos do meio ambiente em que o comportamento deve ter lugar. As representaçôes sociais são consideradas "ciências coletivas sui generis, destinadas a interpretação e elaboração do real". Esta deriva do processo de interação entre o individual e o grupo social, configurando a ideia de movimento da sociedade pensante, proposta por Moscovici. (MOSCOVICI apud SÁ, 1993 p. 50).

$\mathrm{O}$ presente estudo, de natureza qualitativa, refere-se a um processo de investigação acerca das práticas profissionais no âmbito do SUS. A reflexão sobre essas práticas foi o primeiro passo para o desenho deste estudo.

$\mathrm{O}$ cenário foi formado pelos complexos reguladores na cidade do Rio de Janeiro: Centrais de Regulação de Urgência e Central Estadual de Regulação de Leitos. Os sujeitos do estudo são 20 técnicos e gerentes das centrais de regulação, em atuação há mais de um ano. A coleta dos dados foi realizada por meio da técnica de entrevista semiestruturada, orientada por um roteiro temático e questionário de caracterização socioeconômica e de percepções sobre as práticas profissionais, buscando-se apreender as representações sociais do grupo profissional sobre o acesso a açôes e serviços no SUS. Como resultados, destacam-se as seguintes categorias e subcategorias representacionais: a escassez de recursos para o atendimento; as dificuldades de utilização dos fluxos para o acesso; o papel e as práticas da regulação (subdividida em "o desafio da busca da melhor alternativa assistencial" e "o uso de critérios para a priorização do acesso"; a fragmentação e 
a autonomia da regulação; a rede de relações pessoais determinando o acesso; e a ausência de comando único - as ilhas de centrais de regulação.

\section{A escassez de recursos para o atendimento}

Discutiremos a primeira categoria - escassez de recursos para o atendimento -, composta por 224 unidades de registro (UR), representando $24 \%$ do total de URs da análise e que contempla sete unidades de significação. Expressa a escassez de recursos existentes na rede do SUS, o que se revela como uma grande barreira ao acesso a ações e serviços necessários ao atendimento das necessidades de saúde da população.

O primeiro aspecto dessa categoria é que a maior demanda reprimida enfrentada pelas centrais é de leitos de unidades fechadas ou, mais especificamente, leitos de CTI. Nestes, estão englobados tanto os leitos de adultos como pediátricos, com maior relevância quantitativa, porém, entre os de adultos. Não há equidade na distribuição e no acesso aos leitos disponíveis, com carência no setor público e excesso no privado, grande concentração na região metropolitana e somente 5\% das UTIs em hospitais universitários.

Esse quadro exige a reflexão sobre a restrição de acesso aos recursos de alta e média complexidade. Apesar de os indicadores apontarem crescimento da oferta, ainda se caracterizam como insuficientes para as necessidades apresentadas pela população. Faleiros (1997) destaca as decisões complexas que perpassam os diversos segmentos da hierarquia das unidades de saúde e atravessam diversos aspectos a serem considerados: a relação entre as condições e as decisões, o contexto brasileiro da exclusão social e, no atendimento à saúde, algumas opções de ação com seus limites e possibilidades.

$\mathrm{Na}$ verdade nós continuamos no mesmo ponto. $\mathrm{O}$ acesso do paciente ao recurso de alta complexidade, pra manutenção da vida, pra sair de uma situação de risco de vida... [entrevista 5].

Todos nós sabemos que quem tem um problema de saúde está fadado a morrer rapidamente, porque a rede hospitalar ela não atende à demanda como um todo [entrevista 13].

Os conteúdos representacionais nessa categoria estão centrados em dois principais aspectos: na falta de vagas, sendo esta reconhecida como a grande barreira ao acesso, e na falta de recursos de especialidades mais complexas (valorização da alta 
especialização, escassa no dia a dia do SUS, tais como neurocirurgia, especialidades

cirúrgicas, cardiológicas, e outras.). A imagem constituída é a de funil.

\section{As dificuldades de utilização dos fluxos para o acesso}

A segunda categoria, as dificuldades de utilização dos fluxos para o acesso, é composta por 295 URs (32,18\% do total de URs) e 34 unidades de significação, e interpõe o papel institucional e suas práticas.

O acesso à rede de unidades assistenciais se iniciaria a partir da responsabilização por uma área geográfica adstrita, com cobertura integral de sua população. Essa rede assistencial primária é responsável pela entrada do usuário no sistema. Essa lógica de planejamento considera que o uso dos serviços acontece de forma ordenada, regionalizada e racional.

O cotidiano, no entanto, mostra que o pressuposto de existência de uma porta de acesso por meio da rede básica de saúde é fictícia e, na verdade, representa a imposição de diversas barreiras ao acesso da população aos serviços. Os exemplos do não esgotamento dos recursos no primeiro nível de atenção antes do encaminhamento para níveis mais complexos são frequentes e caracterizam a pouca utilização da tecnologia leve e a queima de etapas no processo de cuidado em saúde. Esse quadro exige a reflexão sobre a restrição de acesso aos recursos de alta e média complexidade, apontando o fracasso dos fluxos existentes, configurando longas filas de espera para o atendimento pretendido, que não conseguem ser debeladas pelos fluxos normais preconizados. A responsabilização do profissional com o sujeito atendido, com o estabelecimento de um maior compromisso, resulta num encaminhamento mais adequado às necessidades do usuário e com mais informaçôes.

Porque o acesso à saúde básica, ambulatorial, o dia a dia, a prevenção das doenças, o cuidar da saúde é ruim, então ou ele passa realmente mal e vai a uma emergência; ou ele vai à emergência para fazer um atendimento que não é de emergência e gera um transtorno da própria fila de atendimento que é maior do que deveria ser; prevenção, o cuidado [entrevista 03 ].

Os conteúdos representacionais nesta categoria estão centrados: a) no reconhecimento das dificuldades de acesso às "portas e entrada" do sistema; b) na identificação das seguintes portas de entrada no sistema: rede básica, atendimento pré-hospitalar fixo e grandes emergências; c) na baixa cobertura assistencial e baixa 
resolutividade da Estratégia Saúde da Família no município do Rio de Janeiro; e d) na dimensão imagética: porta de acesso fictícia através da rede básica de saúde.

\section{O papel e as práticas da regulação}

A terceira categoria se compõe por 295 URs e 34 unidades de significação, representando $32,18 \%$ do total de URs, tendo constituído duas subcategorias: o desafio da busca da melhor alternativa assistencial e o uso de critérios para priorização do acesso.

Para refletir sobre a busca da melhor alternativa assistencial, devemos considerar algumas questôes. A primeira, os pressupostos de interfaces bem articuladas entre as várias instâncias assistenciais e a garantia de pactuaçôes, ao mesmo tempo sustentáveis e flexíveis, de acordo com as necessidades variáveis dos diversos elementos da rede assistencial. Isso se refletiria em mudanças ágeis das referências, de acordo com a variação do quadro de recursos disponíveis e, ao mesmo tempo, em sensibilidade para se alterar o perfil das demandas populacionais.

A segunda questão se refere à caracterização das Centrais de Regulação de Urgências - Centrais SAMU 192 - , que se constituem em "observatório privilegiado da saúde", com capacidade de monitorar, de forma dinâmica, sistematizada e em tempo real, todo o funcionamento do sistema de saúde, devendo gerar informes regulares para a melhoria imediata do sistema de atenção às urgências e da saúde em geral (BRASIL, 2006, p. 62).

Essa premissa pode ser transferida para o complexo regulador. A regulação no contexto assistencial representa um conjunto de processos que visam ao fortalecimento dos princípios do SUS. Ela faz parte da estratégia de facilitar o acesso às tecnologias em saúde, por meio das Centrais de Marcação e Regulação, inseridas no contexto da gestão municipal e estadual, buscando garantir o acesso dos cidadãos à rede de serviços públicos, operacionalizar a hierarquização da saúde em todo o estado, aperfeiçoar a utilização dos serviços de referência nos espaços supramunicipais, segundo os critérios de necessidades de saúde da população, e oferecer a melhor resposta assistencial disponível às demandas existentes. (BRASIL, 2007).

O terceiro e último a aspecto a ser levado em consideração são as necessidades de saúde. Oliveira (2001), analisando as concepções desta, afirma que elas se tornaram mais conhecidas, principalmente aquelas centradas nos aspectos 
psicológicos e somáticos dos indivíduos em suas demandas nos serviços de saúde.

Na base dessas concepções, existe a convicção de que é mais consistente equiparar "necessidades" a "preferências subjetivas", entendendo que só os indivíduos ou grupos particulares sabem de suas demandas e, por isso, são mais capazes do que as instituições coletivas de traçar os objetivos e prioridades que melhor lhes convêm.

[...] a Central passou a expandir o processo da regulação e isso traz [...] toda a dificuldade da rede pública, de atendimento quando a demanda, que já não é pouca, se acresce de uma epidemia [...]. A Central passou a ser um posto de observação avançado, que expôs uma situação que existe e que não era tão clara para quem tem a gestão da coisa toda. Acho que era bastante clara para quem está na ponta, na frente do paciente, lidando com todas as dificuldades [entrevista 05].

A gente consegue visualizar melhor daqui, mas é muito complicado para o colega que está na unidade diante de todas as dificuldades que ele está enfrentando, ele ter essa percepção, então é muito difícil fazer esse trabalho de captação, de tentativa de achar uma vaga, na tentativa de convencer que o paciente tem uma chance maior ele indo para onde a gente tá querendo, do que ficar onde ele já está paciente... [entrevista 17].

A segunda subcategoria que iremos apresentar é o uso de critérios para priorização do acesso. Seu mecanismo de estabelecimento, mesmo nos casos que exigem atendimento imediato, constitui prática alternativa dos reguladores, ou seja, a prática possível diante do cenário de insuficiências diversificadas. Essa impotência gera nas equipes técnicas das centrais uma angústia diária, ao ser responsável pelas escolhas dos acolhidos pelos parcos recursos. A prática ficou conhecida como "escolha de Sofia", e exemplifica uma prática não escolhida..

Sheffer (2006) exemplifica, com as filas nas madrugadas, a crise nos serviços de urgência, o sucateamento de hospitais e a falta de leitos. Para o autor, a tomada de decisão sobre as prioridades de atendimento acontece a partir desse contexto de restrições, mas também a partir de diferentes concepções de prioridades.

O contexto de filas longas e vagas exíguas inseriu outro mecanismo de acesso a esses serviços: os mandados judiciais, que, em grande parte, vêm de clientes de planos privados de saúde que não possuem cobertura de internação maior do que 12 horas após o primeiro atendimento na unidade de saúde privada, requerendo internação em unidades fechadas, como as coronarianas e as de terapia intensiva. Diante da falta de resposta dos planos contratados, os usuários utilizam o mandado judicial para "furar a fila" de vagas. Segundo Ferraz (2007, p. 8), como o acesso ao Judiciário não é igualitário (pessoas de maior renda e educação o acessam com mais facilidade), há uma inevitável transferência de recursos de 
serviços que deveriam atender a todos em condiçōes de igualdade para garantir "integralidade" a apenas alguns. A interpretação equivocada da integralidade resulta, assim, numa perniciosa guerra pelos recursos escassos do SUS. Segundo estimativa do Ministério da Saúde, serão gastos R \$ 500 milhões com essas ações só no ano de 2006. Dessa forma, os mecanismos legais utilizados reforçam a desigualdade do acesso e não apontam para questôes estruturais do sistema, a partir do momento em que não interpretam a necessidade segundo preceitos da universalidade e da equidade. Tais mecanismos oferecem recursos àqueles sujeitos de camadas sociais privilegiadas, conforme apontado, que possuem mais instrumentos para alcançarem o acesso legal.

As mais difíceis é quando você está com vários pacientes graves com um único leito e você tem que fazer a escolha de Sofia; Esse é o nosso dia a dia. E a mais fácil é quando você está com leito pra todos, e aí você pode optar dentro do que o paciente precisa e fazer lá só o quebra-cabeça; É o ideal, e, às vezes, acontece. [entrevista 11].

Todos nós sabemos que trabalhamos num ramo onde quem tem um problema de saúde está fadado a morrer rapidamente, porque a rede hospitalar não atende à demanda [entrevista 13].

A central de leitos de alta complexidade não dá conta da demanda altíssima, não tendo governabilidade para, ao se deparar com uma necessidade, criar automaticamente soluções de reorganização do sistema. Nessa direção, podemos acrescentar a desresponsabilização de profissionais das unidades de emergência, que realizam a solicitação de vaga à central quase que na imediata chegada do paciente à unidade, mesmo antes de uma estabilização do quadro. Esse mecanismo é percebido no grande número de desistências diárias geradas no sistema de vagas de CTI, por melhora clínica ou sem perfil para o tipo de vaga solicitada. Ao nosso ver, esse comportamento do médico gera uma fila de solicitações que não correspondem em seu todo a necessidade de CTI,correspondem a uma estratégia de corresponsabilização de outras hierarquias pela assistência do doente. Assim, se o paciente apresenta melhora, a unidade de saúde que realizava o atendimento se caracteriza como bem-sucedida; no entanto, se evolui insatisfatoriamente, há corresponsabilidade da instância superior - no caso, a central de vagas, que não disponibilizou em tempo hábil a vaga solicitada.

Segundo Arruda (2002), essa realidade demonstra contradições entre as práticas dos profissionais das emergências e a dos profissionais das centrais de regulação, representadas nas regras estabelecidas pelos sujeitos e seus discursos e 
práticas, atuantes no mesmo campo social de saúde enquanto atores e sujeitos sociais

que acabam definindo subcampos, tendo em vista as especificidades das diferentes práticas envolvidas nesses processos e sua posição, tanto nas relações de força quanto na capacidade de olhar mais amplamente o sistema. Explicita-se, ainda, o fator individual operando o sistema, quando o profissional da assistência acessa a CR para repassar a responsabilidade da ação à hierarquia "superior" do sistema.

\section{A fragmentação e a autonomia da regulação}

A quarta categoria a ser apresentada é a fragmentação e a autonomia das práticas de regulação, composta por 30 URs e 11 unidades de significação, 3,27\% das URs.

Devemos resgatar a discussão de outro modelo de atendimento pré-hospitalar móvel, também muito difundido: o norte-americano, que se baseia na atuação de profissionais intitulados paramédicos, com atuação, em geral, sem supervisão médica e sem regulação (BRASIL, 2006) Esse modelo de atendimento caracteriza uma ação de resgate e não contempla a abrangência da ação de regulação, como elo dos diferentes níveis do sistema de saúde.

O modelo parece ter inspirado a coordenação do SAMU, que, a partir de dezembro de 2008, promoveu uma mudança de paradigmas, com a fusão completa da central de regulação SAMU-GSE. Essa operação de unificação tentou mesclar os conceitos de regulação medica do SAMU com a série histórica de resgate do GSE. Esse processo culminou na divisão da regulação médica do SAMU do Rio de Janeiro em primária e secundária.

Tal diferenciação estabeleceu uma dicotomia e fragmentação da regulação. O regulador civil passou a realizar o contato exclusivo com a população, denominado agora de regulador primário, com as funções de realizar a triagem e estabelecer orientações médicas ou envio de viatura. O regulador militar, chamado secundário, não tem contato com a população atendida, restringindose a definir, com a equipe de socorro, a continuidade do atendimento iniciado pelo médico primário e definindo a remoção ou permanência do paciente em residência. Essa nova diretriz foi ainda acompanhada da retirada do suporte de medicamentos das viaturas básicas, que são a maior parte da frota, restringindo, assim, a ação domiciliar do SAMU. As implantações do sistema móvel e do préhospitalar têm a expectativa de diminuir a demanda das emergências hospitalares (BITENCOURT; HORTALE, 2007). 
Nessa direção, a militarização do SAMU redefiniu a regulação numa nova ótica. Além de restringir a visão global do sistema, interferiu na possibilidade de reduzir a demanda das emergências hospitalares, com a restrição do atendimento domiciliar. Os principais conteúdos representacionais a destacar são a fragmentação da assistência que se estabelece em vários níveis, desde a organização do atendimento, e a falta de informações da disponibilidade diária de especialistas nas urgências, ou da malha de viaturas da assistência ou ainda na própria rede de assistência.

A dimensão da constituição representacional se estabelece na percepção da falta de relação entre o regulador e a equipe de atendimento, no caso do SAMU, o que interfere diretamente nos objetivos da central de fortalecer uma rede de atenção que determina o fluxo dos pacientes no sistema. A dimensão imagética da desarticulação do processo de trabalho em equipe, que fomentaria a base do processo de rede de trabalho e de assistência, não permite o exercício da ferramenta estruturante e a objetivação da missão da regulação.

\section{A rede de relaçóes pessoais determinando o acesso}

A quinta categoria do estudo trata da rede de relaçôes pessoais determinando o acesso. Ela é composta por 58 URs, que representam 6,32\% e seis temas do total, contemplando uma das facetas institucionais, na qual o julgamento do grupo implica uma prática específica, a de responsabilização pessoal no acesso, desenvolvida por meio das redes de relaçóes pessoais determinando o atendimento. As práticas da regulação do acesso contemplam as diversas faces da ação profissional e perpassam diversos aspectos operacionais da atividade. Um dos que são ressaltados nesta categoria resulta da relação entre os poucos recursos disponíveis e a demanda altíssima, além do mau funcionamento das rotinas de trabalho definidas, acarretando iniciativas pessoais de responsabilização e resolução das demandas apresentadas pelos usuários.

As iniciativas pessoais demonstram a atitude de compromisso da equipe de regulação, que, ao se comprometer com as necessidades da população, se torna coparticipante de suas dificuldades e angústias.

Diante do quadro traçado, de insuficiência de recursos e de práticas de acobertamento das vagas existentes, a responsabilização pessoal pelo acesso acaba sendo a resposta humana possível, desencadeada pela angústia que esse cotidiano 
imprime aos gestores da regulação. $\mathrm{O}$ processo de responsabilização passa a se

inserir no próprio processo de trabalho do gestor e do médico regulador, sendo naturalizado em função da frequência com que é utilizado. No entanto, configurase como uma demonstração da insuficiência e incapacidade de resposta do sistema.

Mais difícil é você ficar com o paciente grave na fila, ligar pra tudo quanto é lugar e não conseguir, saber que neste paciente a chance de morrer é muito grande, como o caso de CTI. A gente se sente impotente [entrevista 04].

Você não consegue só verbalmente, só argumentando, impondo, exercer seu papel de regulador, embora você tenha que assumir qualquer tipo de responsabilidade sobre qualquer coisa que você fale. Há muita pressão, há muita responsabilização em cima do médico regulador, mas existem muitos impasses e muitas dificuldades que você enfrenta na execução do serviço [entrevista 12].

Como nem sempre essa captação é satisfatória, muitas vezes muitos leitos são omitidos. Eu como coordenador tenho de estar ligando para os chefes dos CTIs ou até pra os diretores desses hospitais cobrando esses leitos, coisa que não deveria ser assim. Deveria ser: ou tem o leito ou não tem. Então o que acontece muito: 'Ah! não tenho...', mas se, de repente, o coordenador ligar pro diretor, ele dá um jeito e aparece um leito, ou se o superintendente ligar pro diretor, aí dá um jeito e aparece leito. Mas não era pra ser assim, era pra ser da seguinte forma: ou tem ou não tem, não é isso? [entrevista 14].

A prática das centrais é a de, a todo momento, buscar a melhor alternativa assistencial; no entanto, os mecanismos formais, organizativos e pactuados são incapazes, isoladamente, de responder às necessidades impostas cotidianamente. Dessa forma, diversos caminhos, distantes do preconizado da regulamentação, são utilizados com o intuito de permitir o acesso dos usuários ao sistema. A responsabilização pessoal pelo acesso acaba resultando na necessidade - pessoal e individual - de resolução da demanda colocada, o que se dá por meio das redes de relações pessoais determinando o atendimento. A estratégia habitual são os contatos pessoais entre os profissionais da rede de saúde, que, a partir das relações cotidianas das equipes, acabam realizando uma gestão paralela, tentando neutralizar as barreiras impostas ao acesso.

Pode-se ainda reconhecer que, nos serviços de saúde, há uma multiplicidade de redes operando em conexões diversificadas, em diferentes direções e sentidos, construindo linhas de produção do cuidado em saúde. Para Franco (2004), a cartografia do trabalho vivo é composta por muitas linhas em conexão, que se abrem em múltiplas direçôes. Isso lhe confere uma característica simultaneamente caótica, revolucionária e, potencialmente, instituinte. 
O compartilhamento de valores, ideias e, portanto, representações pode atuar como facilitador dessas relações interindividuais, trazendo subsídios para a construção de certa forma de autonomia e de responsabilização na equipe de regulação. Os gestores e técnicos das centrais de regulação se colocam na posição de elo entre os elementos do sistema (sócio-organizacionais) e os clientes (individuais), interagindo e facilitando o acesso da população aos serviços, demonstrando sua capacidade de atuar como estruturantes e potencializadores desse acesso.

Esses elementos são considerados vitais, pois permitem incluir informações coletivas - como a cultura - na conformação do modo de organização das práticas, permitindo, com isso, maiores chances de aceitação e identificação com o processo de trabalho desenvolvido pelos trabalhadores de saúde. Estes, por sua vez, terão mais possibilidades de desenvolver alternativas criativas de enfrentamento dos problemas não resolvidos pela estrutura institucional.

\section{Ausência de comando único}

A próxima categoria que se apresenta neste estudo é a ausência de comando único: as ilhas de centrais de regulação.

Esta categoria foi composta por 19 URs, perfazendo 2,08\% do total, e uma unidade de significação, tendo sido definida em função da sua importância qualitativa para a análise do objeto em estudo. Trata da ausência de comando único do SUS no Rio de Janeiro, implicando realização de ações fragmentadas de regulação.

Isso é explicitado na caracterização das "ilhas de centrais" estadual, municipal e do SAMU/GSE, que realizam ações fragmentadas de regulação, não concretizando um "complexo regulador".

Numa federação como o Brasil, não há relação hierárquica entre os entes federativos, e a descentralização de políticas representa antes uma "não centralização", que requer a competência de cada esfera de governo e o desenvolvimento de ações coordenadas. (MACHADO, 2002, p. 506). A descentralização consiste na redistribuição de responsabilidades e decisões relativas às ações e serviços de saúde entre os entes federados. O comando único (ou direção única) em cada nível de governo não deve, todavia, prescindir da ação integrada entre os gestores do sistema nos três níveis de governo. 
No entanto, aspectos locais e regionais devem ser levados em conta com vistas à eficácia das políticas públicas. Alguns deles diferenciam 100 dos 5.600 municípios brasileiros, aqueles com características de grandes metrópoles, e que precisam dar conta da linha de cuidado que ultrapassa seus limites geográficos. Isso requer um Estado forte e solidário, que tente romper os problemas históricoestruturais do sistema de saúde.

\section{Considerações finais}

A fragilidade do sistema público de saúde fica exposta, e as práticas nas centrais de regulação se tornam pouco efetivas e dependentes de mecanismos não formais de ação. Observa-se um SUS menos consolidado, quando comparado a municípios que enfrentam dificuldades no acesso às ações do sistema público de saúde de forma unificada, regionalizada e hierarquizada.

As centrais de regulação são espaços privilegiados para observação do sistema e podem ser capazes de ações efetivas e ágeis, facilitando o acesso aos serviços e propiciando um canal sensível para o atendimento das demandas de saúde da população. Os recursos escassos impostos diariamente à equipe da regulação fomentam uma forte imagem de barreira e incluem no processo de trabalho a face dramática da regulação, conhecida como "escolha de Sofia": os fluxos paralelos para a efetivação da ação profissional ou, ainda, tentativa de resolução das necessidades. Estes criam outra rede, uma rede de relações que atravessa os diferentes componentes do sistema e se alinhava por meio dos contatos pessoais, que são fortes elos da ação cotidiana da regulação.

O grupo estudado reconhece a fragmentação do trabalho imposta pela Central de Urgência, que minimiza a capacidade de ação sobre os fluxos, como também a própria visão do sistema regulatório como um todo, reconhecendo-o como elemento de embricamento do sistema, resultando na não governabilidade das ações pelos técnicos das centrais. Os atores da central reconhecem as dificuldades de acesso à rede básica, o atendimento pré-hospitalar fixo e as grandes emergências como portas do sistema. Esse cenário está inserido na baixa cobertura assistencial e na baixa resolutividade da atenção primária em saúde no município do Rio de Janeiro. Este é um dos elementos percebidos como entrave ao funcionamento do sistema: a atitude reflexiva sobre o acesso organizado que 
qualifica a assistência, mas por si só não garante os demais aspectos da saúde da população. Nessa direção, a discussão nos remete à questão da equidade como uma das respostas necessárias, quando levamos em conta as diferenças sociais do país. Assim, o elemento "desassistido" passa a ser um critério de priorização na prática cotidiana das centrais de regulação.

A credibilidade do grupo de profissionais no importante papel da central como facilitadora do acesso, ao reconhecer as centrais como observatório do sistema, capaz de descortinar as reais potencialidades e dificuldades da rede de assistência, à medida que a regulação assistencial busca organizar a oferta de serviços, exige que sua interface vá além dos sujeitos envolvidos na ação, perpassando a pactuação com os serviços públicos, e também com os privados - estes identificados como necessários à complementaridade assistencial.

A transferência de poder do Estado para a regulação se efetiva permeando o papel de mediadora de recursos, capaz de influenciar, por intermédio do diálogo e do embate cotidiano, o resultado final do acesso dos usuários ao sistema. Como tal, as centrais de regulação são um polo de tensão, pois aglutinam todo o embate da média e da alta complexidade do SUS, procedimentos e internações, confluindo as maiores parcelas do serviço complementar, isto é, as unidades privadas.

A reflexão sobre o modelo de atenção à saúde perpassa a discussão da organização do sistema de saúde municipal, que deve levar em conta como estão distribuídos os serviços nos espaços e suas diferentes complexidades (modelo técnico-assistencial). Esse modelo, segundo Merhy et al. (1992), implica organizar a produção de serviços a partir de determinada combinação de saberes da área, bem como projetos de açôes sociais específicos, como estratégias políticas de determinado agrupamento social. Para Paim (1999), o modelo assistencial consiste na organização das ações para a intervenção no processo saúde-doença, articulando os recursos físicos, tecnológicos e humanos para enfrentar e resolver os problemas de saúde em uma coletividade.

Dentro desta perspectiva, existem modelos que desenvolvem exclusivamente intervençôes de natureza médico-curativa, outros que incorporam açôes de promoção e prevenção da saúde, os que suportam serviços que simplesmente atendem às demandas, aguardando os casos que chegam espontaneamente e, finalmente, aqueles que atuam ativamente sobre as necessidades dos usuários, independentemente de sua demanda. 
O modelo de assistência em funcionamento em nossa cidade precisa ainda galgar diversos degraus na busca de soluções que levem em consideração as características locais e regionais de uma metrópole com uma grande rede de assistência implantada, mas em grande parte sucateada. Dessa forma, o usuário do sistema, ao buscar o acesso aos serviços de saúde, é interpelado por situações de emergência, e mesmo em situações menos prementes, os critérios para sua inclusão são determinados por proximidade ou disponibilidade do recurso demandado.

Fica aqui apontada outra questão já exposta por Franco (2004), segundo a qual o aumento da disponibilidade de procedimentos secundários, por si só, não diminui o estrangulamento do acesso. Os encaminhamentos logo se tornam mecânicos, comuns do atendimento médico-curativo, desgastando-se pela baixa resolutividade, pois, em sua maioria, não são feitos com indicações precisas e não mudam a qualidade do atendimento. O SUS vem ampliando esses procedimentos, em geral com a contratação da rede suplementar privada. $\mathrm{O}$ que se constata é que a utilização dos procedimentos, mesmo por meio da regulação, quando não acompanhada pela ressignificação desses procedimentos e remodelagem do sistema assistencial, gera o desperdício do recurso e mantém a baixa resolutividade e as filas. Enquanto a solicitação acontece num processo de responsabilização do cuidado, os procedimentos passam a ser usados realmente para esclarecimento diagnóstico, com esgotamento do nível anterior de complexidade e maior precisão da solicitação.

Ao verificarmos esses aspectos, uma das dimensóes que pode garantir o cuidado e o acesso é a integralidade da assistência. Essa perspectiva se apropria de um modelo diferenciado de assistência que deve garantir um olhar não mais exclusivamente programático, mas que seja focado em uma perspectiva de cuidado integral, com as diversas áreas e saberes realizando uma atividade não parcelada, permitindo, assim, uma visão ampla do sujeito assistido, e responsabilizando-se pelo caminhar do usuário pelos fluxos do SUS.

Quanto às diversas dimensões do sistema ou modos de expressão, podemos destacar, além do financiamento, que é sempre o mais discutido, a redução da resolutividade das práticas. Isto nos remete às expectativas das pessoas em relação à saúde e à questão ética do valor da vida, da dissociação entre o discurso dominante e a experiência cotidiana. Nessa dimensão, identificamos que passaram a ser cada vez mais questionados o volume e a prioridade da aplicação dos recursos 
públicos em saúde. A discussão se intensifica em relação aos recursos destinados a assegurar a prestação de atenção médica a populações cada vez mais idosas, já excluídas dos processos de trabalho e necessitando sempre de procedimentos de complexidade tecnológica e custos elevados.

O Governo Federal vem apresentando, em documentos oficiais, mecanismos de ordenação da assistência no SUS, com o propósito de ajustar a oferta disponível às necessidades do cidadão. Nesse ponto de vista, trata-se de uma regulação baseada na oferta, mas também compreende mecanismos voltados para a demanda, quando propõe critérios para priorização e organização de fluxo dos pacientes.

A inclusão de informações coletivas, como a cultura, na conformação do modo de organização das práticas, permite maiores chances de aceitação e identificação com o processo de trabalho desenvolvido pelos trabalhadores de saúde. Estes, por sua vez, terão maiores possibilidades de desenvolver alternativas criativas de enfrentamento dos problemas não resolvidos pela estrutura institucional. O desenvolvimento de um modelo de atuação na central de regulação com atribuições ampliadas - não só de regular, mas de avaliar a oferta de serviços, incluindo em suas finalidades orientar os pacientes para consulta, apoio diagnóstico e internações - pode propiciar uma organização da oferta e ainda permitir o gerenciamento pelos gestores.

Assim, a regulação, enquanto estratégia de gestão do sistema, opera a transversalização do objeto-acesso por meio das representaçóes dos quatro grupos sociais envolvidos - os gestores, os profissionais (técnicos e gestores das centrais), os serviços (tanto públicos como privados) e os usuários - apresentando variações em função do grupo ao qual nos referimos.

Para Sabroza (2001), em sistemas complexos como os da saúde, durante as análises das crises, temos que considerar sua natureza e suas dimensões, diferenciação nem sempre fácil desde o início. A crise atual da saúde mais se assemelha àquelas de desenvolvimento, nas quais as diferentes estruturas se encontram em estágios evolutivos distintos, muitas vezes se apresentando em contradição, ainda que temporariamente. Ao contrário de conceitos bem estabelecidos, demarcados por limites que explicitam suas condições, os conceitos imprecisos são definidos a partir de questões centrais, ou atratores, e de suas interaçôes com outros conceitos com os quais se relacionam, sempre a partir de perspectivas definidas em determinado período histórico. 
No grupo estudado, conceitos como equilíbrio, capacidade de realização e bem-estar fazem parte da forma como se representam o acesso e a regulação, embora não sejam suficientes para delimitar completamente o conceito de acesso à saúde. Igualmente, "doença", "sofrimento", "incapacidade" e "não atendimento de necessidades de saúde" são conceitos externos que, por contraste, permitem a aproximação ao conceito de acesso e sua compreensão.

O termo "construção" foi utilizado para destacar que, embora fazendo parte de uma realidade objetiva, a categoria saúde só emerge a partir de sua elaboração por atores sociais concretos, no movimento das relações das pessoas entre si, em grupos sociais particulares e em sociedades mais gerais. Sua representação exige certo grau de abstração que não parece relevante quando a questão se refere apenas à descrição de condições presentes e atuais, esta muito mais vinculada a uma concepção de "vir a ser", de objetivos a serem alcançados, e a um projeto de saúde, seja em uma perspectiva individual ou social.

A realidade não é determinada a priori, mas o é, de qualquer maneira, pela ação dos sujeitos e, em última análise, pelas representações construídas nas relações e nas comunicações cotidianas. Destaca-se a importância da teoria das representações sociais no estudo do acesso ao SUS, uma vez que, dependendo de como esses técnicos e gestores se apropriam do campo da regulação e de como julgam o acesso universal e os princípios fundamentais do SUS, construirão suas práticas. Nesse sentido, destaca-se que um conteúdo representacional significativo identificado foi a missão de fortalecimento das diretrizes do SUS, associada às centrais de regulação, exposta na busca de ampliação do acesso e na equidade da distribuição dos recursos disponíveis. ${ }^{1}$

\section{Referências}

ARRUDA, A. Teoria das Representações Sociais e Teorias de Gênero. Cadernos de Pesquisa, São Paulo, n.117, p.136, nov.2002.

ABREU, A.; JESUS, W.L.A. Revisão sistemática sobre o conceito de acesso nos serviços de saúde: contribuições do planejamento. Revista Ciência \& Saúde Coletiva, Rio de Janeiro, v.12, p.654-658, 2006.

BITTENCOURT, R.J.; HORTALE, V.A. A qualidade nos serviços de emergência de hospitais públicos e algumas consideraçôes sobre a conjuntura recente no município do Rio de Janeiro. Cienc Saúde Coletiva, v.12, n.4, p.929-934, 2007. 

- Ministério da Saúde. MS/SE/DAD/Coordenação-Geral de Apoio à Implementação de Políticas de Saúde/Núcleo de Coordenação da Avaliação de Desempenho do SUS. Oficina sobre Avaliação de Desempenho do SUS. Relatório Final. Brasília, agosto de 2004. Disponível em: http://portal.saude.gov.br/portal/arquivos/pdf/documento\%20politica.pdf. Acesso em: mai.2008.

Ministério da Saúde. Secretária de Atenção a Saúde. Departamento de Atenção Especializada. Regulação Médica das Urgências. Série A. Normas e Manuais técnicos, Brasília Editora do Ministério da Saúde, 2006.

Conselho Nacional de Secretários de Saúde. Sistema Único de Saúde. Conselho Nacional de Secretários de Saúde. Brasília: CONASS, 2007. 291 p. Para entender a gestão do SUS. Coleção Progestores. Disponível em www.saude.al.gov.br/files/pactopelasaude/ manuais/para_entender Acesso em: jul.2008.

- Ministério da Saúde. Secretaria executiva. Comitê Nacional de Avaliação de Desempenho do Sistema de Saúde Comitê Nacional de Avaliação de Desempenho do Sistema de Saúde Brasília, 2007. Disponível em: http://portal.saude.gov.br/portal/arquivos/pdf/ documento\%20politica.pdf. Acesso em: 5 set.2008.

FALEIROS, V.P.Prioridade versus escassez de recursos em saúde . Bioética, v.5, n.1, p.3540, 1997.

FERRAZ, O.L.M. De quem é o SUS? Folha de São de Paulo. São Paulo, 20 dez. 2007.

FRANCO, T.B.; MAGALHÂES JÚNIOR, H. Integralidade na assistência à saúde: a organização das linhas do cuidado. In: - O Trabalho em Saúde: olhando e experienciando o SUS no cotidiano. São Paulo: Hucitec, 2004.

MACHADO, C.V. Regulação da Política Nacional de Saúde: estratégias e tendências. In: NEGRI, B.D.; ÁVILA, O. Sistema Único de Saúde em dez anos de desafio. Campinas: Sobravime, 2002.

MERHY, E.E.; CECÍLIO, L.C.O.; NOGUEIRA, R.C. Por um modelo tecno-assistencial da política de saúde em defesa da vida. Cadernos da 9a. Conferência Nacional de Saúde. Descentralizando e Democratizando o Conhecimento. V. 1. Brasília,1992.

OLIVEIRA, D.C. A Enfermagem e as necessidades humanas básicas: o saber/fazer a partir das representaçôes sociais. 2001.225f. Tese (Professor Titular) - Faculdade de Enfermagem, Universidade do Estado do Rio de Janeiro, Rio de Janeiro, 2001.

PAIM, J.S. Políticas de Descentralização e Atenção Primária à Saúde. In: ROUQUAYROL; ALMEIDA. Epidemiologia e saúde. 5ed. Rio de Janeiro: Medsi, 1999. p. 489-503.

SCHEFFER, M.; ROSENTHAL, C. Aids e ética. In: SEGRE, M. (Org.). A questão ética e a saúde humana. São Paulo: Atheneu, 2006, p. 105-122. 
SÁ, C.P. Núcleo Central das Representaçôes Sociais. Petrópolis: Vozes, 1993. 189p.

SABROZA, P.C. Concepções Saúde Doença, 2001. Disponível em http://www.abrasco. org.br/...\%20P\%20. Acesso em: ago. 2009.

\section{Nota}

${ }^{1}$ A.R.B. Gawryszewski e D.C. de Oliveira participaram da concepção da pesquisa, construção dos instrumentos de coleta de dados, processo de tratamento e análise destes e discussão dos resultados oriundos de sua realização. Ao mesmo tempo, a primeira realizou a coleta de dados nos distintos cenários. A.M.T. Gomes participou da análise dos dados e do processo inferencial dos resultados. 


\section{Access to SUS: representations and practices of professionals developed in Regulation Centers}

The universalization of actions and services, promoted by the SUS, has been characterized as exclusionary and accompanied by rationalization of funding and inclusion of all people in public health care. This study analyzes the policy hierarchy of SUS as a mechanism for planning, through the institutional and professional practices developed in the Regulation Center. The goal is to understand and analyze the social representations of actions and access to health services by technicians and managers in these centrals in the city of Rio de Janeiro. The field of study was the Emergency Regulation Center and State Regulation of Beds. We interviewed 20 subjects and employed content analysis. The results highlight the following representational categories: the attitude of the organization and flow to access, roles and practices of regulation, fragmentation of the autonomy of regulation, determining the relationship network access, and no single command. The fragility of the public health system has exposed itself, and practices in the regulation center are ineffective and dependent on non-formal mechanisms of action. There is a less consolidated SUS in Rio de Janeiro when compared to municipalities experiencing that advance in a unified manner, regionalized and hierarchical access to the actions of SUS. It is noteworthy that the regulation centers are privileged spaces for observation of the system and can take effective action and agile, facilitating access to services and providing a sensitive channel to meet the health demands of the population.

Key words: Brazilian Public Health System, Social representation, Health Policy. 